\title{
Manifesto da ABENEFS: alinhando a formação inicial em Educação Física às necessidades do setor saúde
}

\author{
ABENEFS manifest: Aligning the Physical Education undergraduate \\ courses to the health sector needs
}

Associação Brasileira de Ensino da Educação Física para a Saúde

\section{Introdução}

A Associação Brasileira de Ensino da Educação Física para a Saúde (ABENEFS), com a liderança dos profissionais de Educação Física Adalberto Aparecido dos Santos Lopes, Alex Antonio Florindo, Douglas Roque Andrade, Leandro Martin Totaro Garcia, Lisandra Maria Konrad, Rogério César Fermino e Wallacy Milton do Nascimento Feitosa, e com a participação de seus associados e participantes do II Congresso Brasileiro de Ensino da Educação Física para a Saúde, redigiram um manifesto com o desejo de contribuir com sugestões para que os cursos superiores de Educação Física, seus docentes, profissionais de serviços de saúde e a própria ABENEFS ampliem e potencializem seus esforços na formação inicial de estudantes de Educação Física para atuarem no setor saúde.

Acreditamos que a comunidade de autores e leitores da Revista Brasileira de Atividade Física e Saúde, em sua atuação profissional e em suas redes de contatos profissionais, podem influenciar positivamente o processo de formação inicial nesse campo de atuação.

\section{MANIFESTO DA ABENEFS: alinhando a formação inicial em Educação Física às necessidades do setor saúde}

A Associação Brasileira de Ensino da Educação Física para a Saúde (ABENEFS) tem como objetivo desenvolver e aprimorar a formação inicial e continuada do profissional de Educação Física com ênfase em saúde. De acordo com as suas atribuições e em consonância com os desafios atuais na formação para a atuação no setor saúde, este manifesto foi elaborado para sugerir como diversos segmentos podem colaborar para uma formação inicial em Educação Física mais voltada às necessidades do setor saúde.

O manifesto está divido em quatro seções, cada uma destinada a um público específico:

- Coordenações de Instituições de Ensino Superior em Educação Física;

- Docentes de Instituições de Ensino Superior em Educação Física; 
- Profissionais dos serviços de saúde;

- Diretoria da ABENEFS.

\section{A organização e histórico do manifesto}

O manifesto foi construído com base nos valores da ABENEFS, como acessibilidade aos atores envolvidos no processo de ensino-aprendizagem-trabalho e a aproximação com diversos saberes e práticas. Entre esses saberes e práticas estão os princípios, diretrizes e ações do Sistema Único de Saúde, a educação interprofissional em saúde, a Saúde Coletiva, a Educação Física e atividade física relacionada à saúde. $\mathrm{O}$ processo de redação e desenvolvimento do manuscrito foi coletivo e aberto aos associados da ABENEFS e participantes do II Congresso Brasileiro de Ensino da Educação Física para a Saúde (II COBENEFS), contendo cinco fases:

1) Planejamento e organização inicial;

2) Coleta das opiniões de todos os associados;

3) Elaboração da primeira versão;

4) Revisão e elaboração da segunda versão;

5) Revisão e elaboração da versão final.

$\mathrm{Na}$ primeira etapa, ocorrida em maio de 2015, foram convidados associados da ABENEFS para coordenar cada seção do manifesto. Completando o grupo de trabalho, os coordenadores do II COBENEFS também participaram do processo, enquanto apoiadores. A segunda etapa ocorreu nas duas primeiras semanas de junho de 2015, quando todos os associados da ABENEFS puderam participar do processo de construção do manifesto, via formulário eletrônico, contribuindo com sugestões em quaisquer das quatro seções do documento. Vinte e nove associados contribuíram nessa etapa, com mais de 50 sugestões para cada seção. Na terceira etapa, conduzida na última quinzena de junho de 2015, os coordenadores de cada seção do manifesto sumarizaram o que fora sugerido pelos associados e elaboraram a primeira versão do documento. Para tanto, foram seguidos os seguintes passos:

1) Transferência das sugestões do formulário eletrônico para um documento de texto;

2) Leitura geral com o objetivo de tentar identificar diferentes subgrupos de sugestões;

3) Geração de subgrupos;

4) Análise de conteúdo de cada relato para posterior realocação deles em um dos subgrupos;

5) Releitura atenta de todas as sugestões para sintetizá-las em ações a serem sugeridas, com utilização da taxonomia de Bloom;

6) Nova releitura para refinamento das ações.

Em 3 de julho de 2015, durante o II COBENEFS, a primeira versão do manuscrito foi então disponibilizada ao público e discutida, contando com o envolvimento dos associados e participantes do evento (presencial ou virtualmente). Durante o mês de julho de 2015, o documento foi revisado pelos coordenadores à luz do que fora discutido no evento. Finalizada a revisão do documento inicial, uma segunda versão do documento foi encaminhada aos associados da ABENEFS e participantes do II COBENEFS para a última rodada de sugestões, que ocorreu de 20 de agosto a 8 de setembro de 2015, via formulário eletrônico. A versão final 
do manifesto foi então redigida e em $1^{\circ}$ de outubro de 2015 aprovada pelos coordenadores, dando início à etapa de diagramação e disseminação do documento pela ABENEFS.

\section{Ações que podem ser adotadas por COORDENAÇÕES DE INSTITUIÇÕES DE ENSINO SUPERIOR EM EDUCAÇÃO FÍSICA para alinhar a formação inicial em Educação Física às necessidades do setor saúde}

1) Rever o projeto político pedagógico do curso de forma a garantir espaço para o campo da Saúde Coletiva e para o Sistema Único de Saúde (SUS) com disciplinas, estágio supervisionado e como tema transversal, propondo atividades interdisciplinares, organizando eventos, fortalecendo vínculos com o SUS, incrementando ações no ensino, na pesquisa e na extensão e garantindo a educação continuada para os docentes;

2) Criar e fortalecer parcerias e desenvolver ações regulares com associações e órgãos públicos e serviços específicos da área da Saúde Coletiva;

3) Fomentar pesquisas orientadas para a e com ênfase na promoção da saúde;

4) Criar e fortalecer os projetos de extensão universitária em Saúde Coletiva, como experiências no campo prévias ao estágio curricular;

5) Investir em programas específicos de formação na graduação, como os programas PET-Saúde e Pró-Saúde, e incentivar a continuação da formação nas residências multiprofissionais;

6) Possibilitar e disseminar a formação integrada com outros cursos da área da saúde;

7) Aproximar os serviços de saúde e as Instituições de Ensino Superior para, em conjunto, pensar e definir estratégias aplicáveis às necessidades do serviço. É importante ampliar o olhar sobre o processo de cuidado com a saúde na comunidade, aprimorar a forma de avaliar e monitorar as ações em saúde;

8) Qualificar o ensino, pesquisa e extensão com intuito de fortalecer a atuação do profissional de Educação Física na saúde e a formação de novos profissionais para atuarem na área da Saúde Coletiva.

\section{Ações que podem ser adotadas por DOCENTES DE INSTITUIÇÕES DE ENSINO SUPERIOR EM EDUCAÇÃO FÍSICA para alinhar a formação inicial em Educação Física às necessidades do setor saúde}

1) Formular e revisar planos de ensino de disciplinas direcionadas à saúde para que incorporem conteúdos e aspectos da Saúde Coletiva;

2) Estimular, quando possível, a inclusão da saúde como tema dos planos de ensino das disciplinas, com diferentes enfoques;

3) Estimular a participação dos estudantes em disciplinas, grupos de estudo, projetos de extensão e pesquisa de outros cursos da área da saúde;

4) Estimular a participação dos estudantes em iniciação científica voltada para a área de atividade física e saúde;

5) Investir em educação continuada com ênfase na Saúde Coletiva e em formas de ensino;

6) Utilizar estratégias diversificadas de ensino e metodologias ativas de aprendizagem para aproximar os estudantes de vivências teórico-práticas no ensino, pesquisa e extensão;

7) Apresentar aos estudantes possibilidades de atuação no campo da saúde;

8) Favorecer experiências inter e multidisciplinares durante a formação dos estudantes, com estágios, tutorias e atividades diversas, como forma de ressignifi- 
cação da prática em saúde;

9) Promover e incentivar a participação dos estudantes em eventos comunitários no setor saúde, com ações voltadas para a orientação, aconselhamento e debate com a comunidade;

10) Discutir as ações, programas, políticas públicas de saúde e as diferentes possibilidades de atuação do profissional de Educação Física na Saúde Coletiva, considerando as propostas do Ministério da Saúde;

11) Conscientizar outros docentes sobre a importância da atuação do profissional de Educação Física no setor saúde;

12) Estabelecer e fortalecer redes de pesquisadores da Educação Física com profissionais de outras áreas da saúde;

13) Auxiliar os coordenadores de curso para que estabeleçam disciplinas e conteúdos sobre Saúde Coletiva e na definição das competências e habilidades necessárias para atuação do profissional de Educação Física nos serviços de saúde.

\section{Ações que podem ser adotadas por PROFISSIONAIS DO SERVIÇO \\ DE SAÚDE para alinhar a formação inicial em Educação Física às necessidades do setor saúde}

1) Aproximar os serviços de saúde e as Instituições de Ensino Superior para, em conjunto, pensar e definir estratégias aplicáveis às necessidades do serviço, ampliar o olhar sobre o processo de cuidado com a saúde na comunidade, aprimorar a forma de avaliar e monitorar as ações em saúde e qualificar o ensino, pesquisa e extensão, com intuito de fortalecer a atuação do profissional de Educação Física na saúde e a formação de novos profissionais para a Saúde Coletiva;

2) Atuar de forma solícita e responsável com a supervisão de acadêmicos em campo de estágio nos diversos cenários de prática na saúde, com intuito de fornecer subsídios para que novos profissionais possam ter experiências positivas;

3) Apropriar-se e contribuir para a definição das competências técnicas do profissional de Educação Física no setor saúde, considerando um contexto que exige conhecimento e habilidade para atuar em equipes multiprofissionais e com uma visão ampliada da Saúde Coletiva;

4) Participar de eventos que integrem profissionais de saúde, secretarias de saúde, Instituições de Ensino Superior, associações e conselhos da Educação Física, para compartilhar experiências e discutir dificuldades e possibilidades de atuação do profissional de Educação Física no setor saúde;

5) Incentivar os Profissionais de Educação Física que atuam no setor saúde a identificar e compartilhar ações e intervenções de promoção da atividade física;

6) Ajudar a definir as prioridades e necessidades dos serviços de saúde para formação inicial, articulação e investigação junto às Instituições de Ensino Superior.

Ações que podem ser adotadas pela DIRETORIA DA ABENEFS para alinhar a formação inicial em Educação Física às necessidades do setor saúde

1) Elaborar e divulgar documentos norteadores sobre a definição do campo de atuação da saúde e suas interfaces com as áreas de conhecimento da Educação Física;

2) Criar, manter atualizada e divulgar uma biblioteca virtual no website com portarias que regulamentam e orientam a atuação do profissional de Educação Física no setor saúde;

3) Oferecer e participar de consultorias, cursos, oficinas, seminários e congressos de forma colaborativa e horizontal, a fim de disseminar experiências e conhecimentos sobre as particularidades das práticas em saúde e discutir a for- 
mação e atuação do profissional de Educação Física com docentes, discentes, profissionais de saúde, políticos, gestores da educação, da saúde, conselhos e associações de classe;

4) Realizar ações de sensibilização junto ao Ministério da Saúde e da Educação e às entidades representativas das Instituições de Ensino Superior sobre o crescimento exagerado de novos cursos de Educação Física, assim como a alta concentração de ofertas nas regiões Sul e Sudeste;

5) Facilitar o diálogo entre o setor saúde, a sociedade civil e as Instituições de Ensino Superior;

6) Manter relação com as secretarias estaduais e municipais de saúde;

7) Garantir, fortalecer e expandir o espaço da ABENEFS nos fóruns de discussão do setor saúde;

8) Apoiar a formação de redes regionais de pesquisadores, docentes e profissionais interessados na formação em Educação Física e Saúde Coletiva;

9) Apresentar propostas de eixos temáticos na área do setor saúde e o perfil profissional esperado que possam ser adotados como referencial pelas coordenações dos cursos de graduação e pelos Núcleos Docentes Estruturantes para possíveis adequações dos currículos de modo que a formação seja organizada para alcançar os objetivos acadêmico-científico, cidadão-político, profissional e do mercado de trabalho.

10) Divulgar amplamente as ações da ABENEFS e garantir maior adesão, representatividade e envolvimento dos associados;

11) Criar espaços nos eventos nacionais para os profissionais dos serviços de saúde debaterem a promoção da saúde e da atividade física conjuntamente com as Instituições de Ensino Superior e grupos de pesquisa na área;

12) Elaborar um documento aprovado pelos órgãos responsáveis (associações e conselhos) para divulgar e esclarecer as competências necessárias e atribuições para atuação do profissional de Educação Física no serviço de saúde.

\section{Considerações finais}

O processo de formação em Educação Física, como deve ser em qualquer área, está em reflexão constante, que, por vezes, resulta em ações bem definidas nos diferentes cenários. Esperamos que esse manifesto inspire e seja traduzido em ações concretas. Acreditamos que só a reflexão e a ação restrita ao seu ambiente de trabalho não são suficientes. É necessário o engajamento político, para influenciar os tomadores de decisão em escolhas que reflitam os anseios de todos os atores envolvidos nesse processo. Como disse Milton Nascimento em sua canção Notícias do Brasil "...ficar de frente para o mar, de costas pro Brasil / Não vai fazer desse lugar um bom país".

A ABENEFS sabe que a produção desse manifesto é uma pequena contribuição, mas a decisão de compartilhar o que pensamos e desejamos potencializará a sua força, na proporção que esse documento seja exposto, discutido e criticado. Esperamos que o manifesto gere mudanças na forma que agimos no processo de formação inicial em Educação Física para o setor saúde. 